\title{
The IoT Solution to Learn English Words
}

\author{
Shogo Aizawa, Motohide Yoshimura \\ Department of Information Systems, Faculty of Information Systems, University of Nagasaki \\ Japan \\ 1-1-1 Manabino, Nagayo-cho, Nishi-Sonogi-gun, Nagasaki 851-2195, JAPAN \\ E-mail:yxsimura@sun.ac.jp \\ http://sun.ac.jp/e
}

\begin{abstract}
We innovate an IoT solution to play the English word learning system. It uses a Raspberry Pi and two NFC readers. You can learn English words in three steps by using our system. First, prepare NFC tags corresponding to English words and illustrations, such as a cat, dog, chicken etc. Next, select a pair of the tag corresponding to an English word and illustration. Finally, hold them over the each NFC reader, then the answer that is correct or incorrect are displayed on a touch panel. Our solution has two aspects. The one is an educational system for children and the other is an IoT toy playing with children. As to the former, the children can learn English words by intuitive operation such as operating the touch panel and holding the NFC tags. As to the latter, they can experience a part of an IoT technology. In this paper, we report findings through the construction of the English word learning system..
\end{abstract}

Keywords: English word learning system, IoT, NFC, educational system, IoT toy

\section{Introduction}

Information and communication technology is now an integral part of our lives. In 2019, 96.1\% of households own mobile terminals, and $83.4 \%$ of households own smartphones, there is more than $80 \%$ of households [1]. The development and spread of ICT has brought about major changes outside the ICT field. The role of ICT in the field of education is also important. In 2020, programming education became compulsory in elementary schools, and the new teaching guidelines for elementary schools announced in March 2017 stated as follows, "In order to cultivate the ability of information utilization, ICT equipment such as computers and networks will be provided at every school. We will equip the appropriate environment to utilize these tools and enhance learning activities [2]." The basic idea of ICT utilization by the Ministry of Education is as follows, "Based on the new teaching guidelines, there are three important aspects. The one is the balanced development of the three pillars of qualities and abilities. The second is the aggressive utilization of ICT as the teaching materials, the teaching and learning tools according to both of the actual conditions of children and schools, and characteristics and learning steps of each subject. The third is the class improvement for the proactive, interactive and deep learning.[3]" In addition to ICT utilization such as efficient and effective presentation using the large presentation screen, the goal is to prepare a terminal for each student and promote learning independently and interactively. By using ICT equipment, it is possible to study efficiently during the limited learning time. Aggressive utilization of ICT is an important issue for enhancing future educational activities.

The utilization of ICT equipment is underway in all subjects. Especially, the use of ICT in English education is being actively promoted, and $99.1 \%$ of schools utilize ICT equipment in English education in elementary schools [4]. However, according to a survey of Japanese children's use of digital devices in schools at OECD PISA 2018, the percentage of students who answered that they did not use ICT devices in their school's "foreign language" class was $67.0 \%$, it is the worst among participating countries [4]. It can be said that the environment in which teachers utilize ICT in English education is in place, but the environment in which students themselves use ICT to learn English is not sufficiently developed. 
In this research, we will develop an English learning system by using ICT, especially IoT. The IoT is a technology that connects things via the Internet, as translated as the "Internet of Things". Simply speaking, it is the immediate reflection of happenings in the real world to the digital world. With this technology, both analog and digital advantages can be leveraged. An IoT toy is the one that incorporates the elements of IoT. By utilizing this element, not only will it attract the interest of children, but it will also be possible for them to experience ICT with simple operations. By using our system, users can learn English while playing and can come into contact with IoT, which is a part of ICT. In this paper, we report the findings obtained in the construction of the system. We will show examples of using English learning tools in Section 2, and describe examples of IoT toys for children in Section 3. In Section 4, we will describes our system using NFC. In Section 5, we will summarize the paper.

\section{Examples of using English learning tools}

\subsection{Current status of English learning}

As in the case of compulsory English education in elementary schools in 2020, the timing to start learning English is getting earlier year by year. Specifically, the "foreign language activities" that were conducted in the 5 th and 6th grades in the teaching guidelines before 2020 will be advanced to the 3rd and 4th grades, and English will be started as a subject of "foreign language" from the 5 th grade. The goal of "foreign language activities", which will be held in three or four years in the elementary school, is to familiarize yourself with English through activities such as quizzes, dance, and singing. By starting to learn English from an early stage, children can take advantage of their flexible adaptability, develop a positive attitude toward communication, and become familiar with English expressions. In addition, more than $70 \%$ of junior high school students wanted to read English words and sentences in elementary school, and felt that they wanted to learn English words among elementary school [5]. By becoming accustomed to English in elementary school, children will be able to acquire a foundation for English education after junior high school, which will lead to improvement of their English proficiency.
Familiarity with English in active English learning in elementary school is very important in learning English after junior high school. The liking and proficiency of English in junior high school has a great influence on the frequency and amount of learning of English [6]. It is effective to "like" English in order to effectively advance learning English. For that purpose, it is necessary for students to "like" English from the English education of elementary schools and to maintain their interest in English. A game that utilizes English is used as a way to invite the interest. It has been found that learning English in combination with games is effective in familiarizing yourself with English and practicing and establishing the vocabulary that is the basis of foreign language activities [7].

\subsection{Flashcard case}

Flashcards are used as teaching materials when you start learning English. A flash card is a set of a card with an illustration and a card with words written on it. It is used in school lessons and English conversation classes, and the teacher can show the illustration card and the English word card at the same time to teach pronunciation, or show only the illustration card and let them answer the English word. You can also incorporate game elements such as playing with listening to English and taking illustration cards like playing cards. Since it is a simple structure, it can be used in various ways by the ingenuity of the teaching side. Currently, various types of flash cards are on sale, so you can choose a flash card that suits your purpose, such as age and type of English words.

There are also flashcards that incorporate ICT elements [8]. A flash card can be displayed on an ICT terminal and used in the same way as a conventional flash card. In addition, since the native speaker's voice is attached, you can hear and acquire the correct pronunciation of the native speaker. By using an ICT terminal, students can be made to hear the correct pronunciation of native speakers without the teacher knowing the correct pronunciation of English.

\section{Examples of IoT toys for children}

\subsection{Overview of IoT toys}

With the development of ICT in recent years, IoT is also being incorporated into toys for children. Products so- 
called IoT toys are on the market. You can experience the world of the Internet with more intuitive operations than using a smartphone or PC, expanding the range of play from the analog world to the digital world. It is also possible to get interested in the ICT field by playing while touching a part of IoT technology. In addition, IoT toys are more attractive than their toys by connecting smartphones, game consoles, and toys via the Internet. IoT toys also have an aspect as educational toys, and are attracting attention as toys that can be learned while playing. It can be said that IoT toys are also very useful as a means to improve their abilities in the present age when programming education is emphasized. Here, we will introduce specific examples of IoT toys in Japan.

\subsection{CORO-PUTER-Ja.}

"CORO-PUTER-Ja." is a wooden IoT educational toy developed by TDS Co., Ltd. [9]. When a wooden hiragana block with an embedded RFID tag is rolled onto a wooden frame with an embedded reader, the reader reads the tag and the hiragana is displayed on a smartphone connected via Bluetooth. This allows you to learn letters and words and get in touch with technology through the play of rolling blocks. Even infants can easily pick up blocks, carry them to the frame, and roll them, so they can learn while playing. It can be said that the strength of IoT toys is that a lot of information can be obtained with this simple operation.

\section{English learning system using NFC}

\subsection{Features of our English learning system}

In this research, we innovate an IoT solution to play the English word learning tool as a framework of English learning by IoT toys and prototype an English learning system for children that aims to integrate English learning and ICT. By using this tool, you can learn English while playing with IoT toys, and you can also experience some of the IoT technologies.

\subsection{Development environment}

In this system, the users proceed the English word learning, while the contents of the NFC tag read by the NFC reader are displayed on the touch panel. The system consists of Raspberry Pi 4, and the OS Raspbian (version 10 (buster)) as the Platform, and two NFC readers and
English words and illustration cards at which the NFC tags attached. Python (version 3.7.3) is used to construct the system. NFC Py (version 1.0.3) is used to operate the NFC reader.

\subsection{System overview}

We will explain the outline of our system. Figure 1 shows the system configuration diagram.



Fig1. System configuration diagram

This tool processes the content read by the NFC reader with Raspberry $\mathrm{Pi}$ and reflects it on the touch panel. Sony's PaSoRi RC-S380 / S is used to read NFC tags, Kuman's 7-inch touch panel is used to display the screen, ZoeeTree S1 portable Bluetooth speaker is used to play audio, and Raspberry Pi 4 is used to process and execute codes. The purpose of this system is to learn the English names of animals. There are two kinds of cards, "Animal Card" with animal illustrations and "Animal Name Card" with animal English names as shown in Fig. 2.

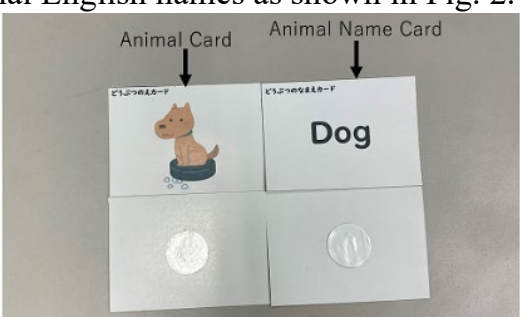

Fig2. Card with NFC tag attached

We attach the NFC tag to the back of each card. In this system, unique IDm of each NFC tag is associated with each of the "Animal Card" and "Animal Name Card", and the correct answer or incorrect answer is determined by pairing two IDm in the code. The NFC tag used for each card is Sanwa Supply's NFC tag (product part number: MM-NFCT). Two NFC readers are prepared so that the "Animal Card" and "Animal Name Card" can be read at the same time. They are decorate as shown in Fig. 3 to clarify the reader on which each card should be placed. 


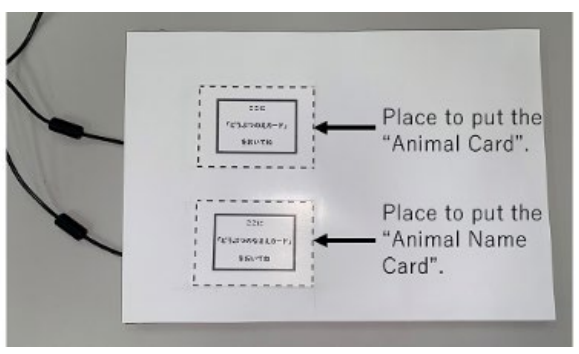

Fig3. Decorated NFC readers

As shown in Fig. 4, place the "Animal Card" and "Animal Name Card" on each reader, and press the "Play" button on the touch panel to execute the code and display the correct or incorrect answers. When reading a card, the IDm of the NFC tag is read, and the illustration and name of the animal on the card corresponding to that IDm are displayed on the touch panel.

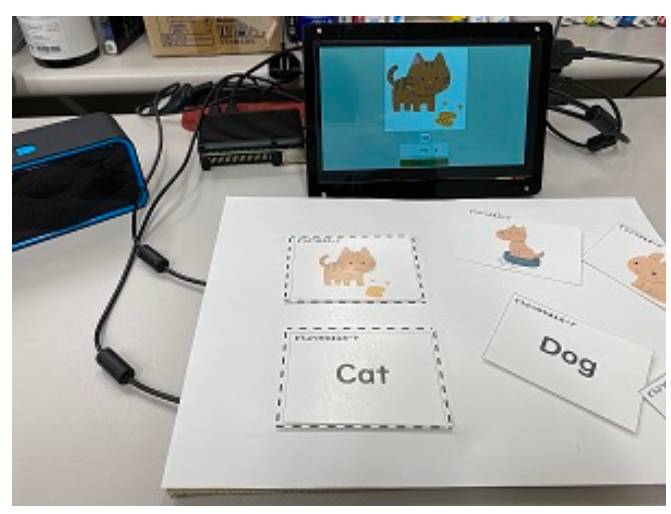

Fig4. Operating environment

\subsection{System behavior}

The user places the "Animal Card" and "Animal Name Card" with the NFC tag attached on the corresponding NFC reader, and presses the "Play" button to confirm the correct or incorrect. In case that the answer is correct, for example, the dog's "Animal Card" and the dog's "Animal Name Card", a sound indicating the correct answer and an illustration $(\bigcirc)$ indicating the correct answer are displayed on the touch panel. In case that the answer is incorrect, for example, a cat's "Animal Card" and a dog's "Animal Name Card", a sound indicating an incorrect answer and an illustration $(X)$ indicating an incorrect answer are displayed on the touch panel. In addition, only if the answer is incorrect, the correct animal bark that matches the "Animal Card" is played through the speaker, and the frame of the "Animal Name Card" on the screen is blinked to suggest another "Animal Name Card". The reason for playing the correct animal bark that matches the "Animal Name Card" is to make it easier to imagine an animal illustration from the bark.

\section{Conclusions}

In this research, we prototyped an English word learning system that integrates English learning and IoT by using NFC tags. Our system can memorize English words and illustrations as a word meaning in combination by reading NFC tags with two NFC readers. In the future, we have a plan to enhance the mechanism so that children can learn with more interest.

\section{References}

1. Ministry of Internal Affairs and Communications, 2020 WHITE PAPER Information and Communications in Japan, 2020, in Japanese.

2. Ministry of Education, Elementary School Programming Education Guide (3rd Edition),

https://www.mext.go.jp/content/20200218-mxt_jogai02100003171_002.pdf(accessed 2020-12-8), 2020, in Japanese.

3. Ministry of Education, Effective use of ICT in teaching each subject, https://www.mext.go.jp/content/20200911-mxt_jogai01000009772_19.pdf(accessed 2020-12-8), 2020, in Japanese.

4. Ministry of Education, Effective use of ICT in teaching foreign languages,

https://www.mext.go.jp/content/20200911-mxt jogai01000009772_13.pdf (accessed 2020-12-8), 2020, in Japanese.

5. Ministry of Education, Current status, achievements, and challenges of foreign language activities in elementary schools,

https://www.mext.go.jp/b_menu/shingi/chousa/shotou/102/s hiryo/attach/1347444.htm (accessed 2020-12-8), 2020, in Japanese.

6. KANEKO Yoshitaka, Educational Implications to Help Students to Enjoy Learning English, Bulletin of Meikai Teacher-Training Support Center, vol.1, pp.1-15, 2018, in Japanese.

7. Chihiro Tachibana, Game activity functions used in the teaching process of elementary school foreign language activities: Focusing on the functions of game activities and the effects of learning, Himeji University Academic Institutional Repository, no.12, pp.9-22, 2019, in Japanese.

8. CHIeru Co, Elementary school flash English words, https://www.chieru.co.jp/lp_english/(accessed 2020-12-8), in Japanese.

9. TDS Co., LTD., CORO-PUTER-Ja., https://www.replug.jp/coro-puter/(accessed 2020-12-8), in Japanese. 